\title{
The Content and Language Integrated Learning Approach in Use
}

\author{
Jindřiška Šulistová ${ }^{*}$
}

\begin{abstract}
The article briefly introduces the CLIL method and its use. The paper explains the terms hard CLIL and soft CLIL. Next, it deals with CLIL specifics, possible advantages and disadvantages. The competence and educational requirements on teachers are mentioned, too. This contribution also contains a sample lesson of recruitment.
\end{abstract}

Key words: CLIL, application, soft CLIL, hard CLIL, advantages, disadvantages.

\section{Introduction}

CLIL (Content and Language Integrated Learning) 'is a term created in 1994 by David Marsh and Anne Maljers as a methodology similar to [but distinct from] language immersion and content-based instruction. It's an approach for learning content through an additional language (foreign or second), thus teaching both the subject and the language. The idea of its proponents was to create an "umbrella term" which encompasses different forms of using language as a medium of instruction.' (Wikipedia, 2013). CLIL is a new didactic approach to teaching subjects integrating two features - linguistic and factual. There are two kinds of CLIL: the so-called hard CLIL and soft CLIL methods. Hard CLIL means that the subject or subject curriculum is taught in a foreign language. However, the main lesson objective is the content objective, not the language, while in the so-called soft CLIL form, the content of the subject is subordinate to the language goal. A higher emphasis is put on learning the language. Briefly said, the CLIL method employs the language to pass on the knowledge from a different (usually non-linguistic) subject.

\footnotetext{
* Jindřiška Šulistová, Institute of Technology and Business in České Budějovice, České Budějovice, Czech Republic; sulistova@ vstecb.cz
} 


\section{The history of CLIL}

The CLIL method was used for the first time at the Jyväskylä Finnish University and also in the Netherlands in the late 90s of the last century. The countries mentioned above emphasize project-based learning when students (from their home countries and from abroad) work in various groups for one semester. As a consequence of the co-operation they are given the opportunity to work with people of different backgrounds and with different native languages. This fact enables them to get used to a wide range of accents.

The CLIL method is said to correspond with the process of being acquainted with the so-called lingua franca and uses it as a communication tool among nations in order to enable everyone to understand each other without having to learn many languages.

\section{The application of CLIL}

As it can be seen in the picture below, CLIL is supposed to develop some necessary competences in the current globalized world, such as

- A multicultural approach is to become more and more common in the current world and to live within one country with speakers of other languages with a different cultural background may be soon considered as a matter of fact. This approach develops communication across cultures.

- Students are offered real-life situations where they are to use English as a communication means and this makes them raise their awareness as to how the language itself is used, as well as cross-cultural awareness. The learners develop their immediate speaking skills with an emphasis on fluency.

- A diversity of methods and materials prepares students to deal with people from different cultural, language, and social backgrounds and to perceive the differences as a part of other culture that enriches them. It enhances teamwork and helps individuals to find their roles in a team. The use of various kinds of materials helps to develop learners' flexibility.

- Excellent materials offer up-to-date study resources available not only for teachers but also for students in various forms. These materials develop learners' orientation in online and printed information. Students are exposed to written and oral resources and, due to that fact, they become aware of different idioms, sayings and fixed expressions used in all sorts of situations.

- Neurodidactics supports ICT application in classrooms and the so-called brain based activities. Learners have the opportunity to learn about their learning styles (e.g. visual, kinaesthetic, auditory) within these kinds of activities and gradually work on developing skills. 
- English (as lingua franca) is employed in the CLIL method in many states apart from those countries where there are more official languages (e.g. Luxemburg). Subjects can be taught there in other languages, too. The matter of English (as lingua franca) in the Czech environment is discussed in the monograph Intercultural Communication (Interkulturní komunikace) by Jan Průcha. He considers the option of other languages more suitable for central Europe, mainly dependent on the neighbouring countries which play a significant role in the selected country's economy. Students develop their skill to learn the target subject through a language (which is not their mother tongue).

- Gender sensitivity is dealt with in David Crystal's book called How Language Works where he says that gender in language has drawn a lot of attention due to the influence of feminism in the USA. Even new words are formed to respect both sexes, such as police officer instead of policeman/policewoman. Learners become aware of the current genderrelated situation and therefore they avoid causing faux-pas.

Fig.1The CLIL Method

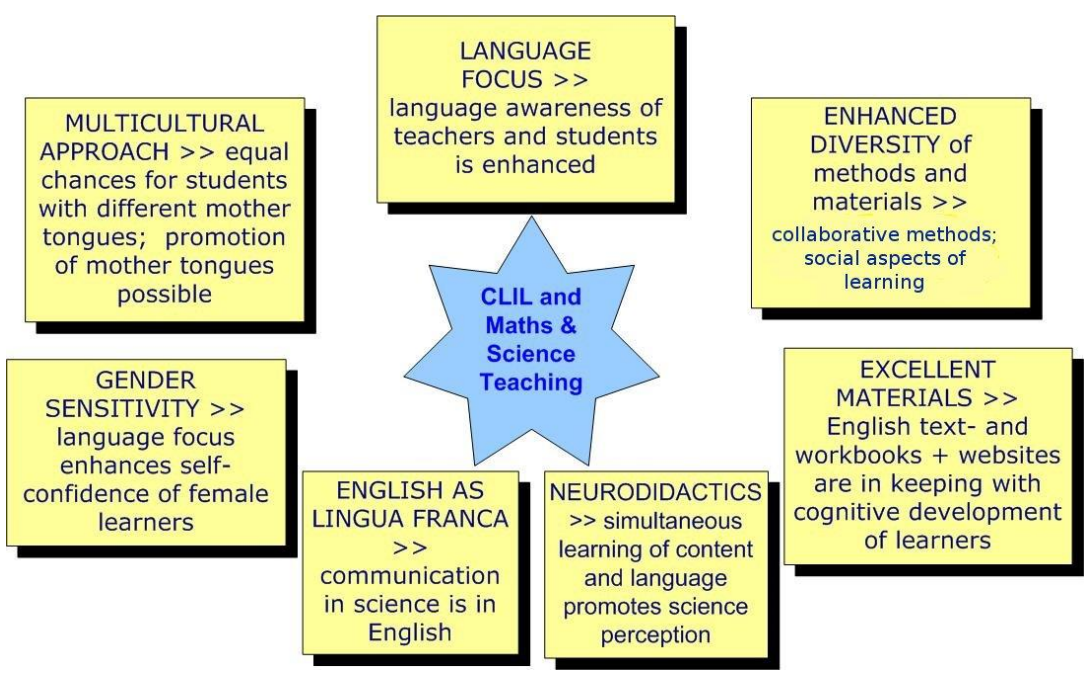

http://www.google.cz/imgres?imgurl=http://sciencemaths-clil.eu/wpcontent/uploads/2010/05/sm_clil_star_mocdified1.jpg\&imgrefurl=http://science maths-

clil.eu/?page_id\%3D2\&h=663\&w=1094\&sz=136\&tbnid=8usnua4lbRgXbM:\&t bnh $=67 \&$ tbnw $=111 \&$ zoom $=1 \&$ usg $=$ = 9lNRUnXJwLJqUSLdCWeXgyUgVq4= $\&$ docid=iW1QxcwMnsKKZM\&sa=X\&ei=QLeDUbz9Jc_KtAaj_ICwCA\&ved= 0CFkQ9QEwBw\&dur=1693, 29/4/2013 
Another consequential feature is the emphasis on active participation of the learners. The teacher's role in the classroom is more concentrated on monitoring and assisting as Kalhous, Obst et al. (2002) recommend in the Learning Pyramid. This way enables the students to remember and experience more as their curiosity is boosted up by certain types of activities (e.g. brainstorming, mingling and matching, filling in the rest of a sentence or a paragraph, etc.).

\section{Advantages and Disadvantages}

CLIL as a teaching method has its advantages but it also has some drawbacks when compared with other approaches.

As for the positive aspects the following ones can be named:

- learning enhances critical thinking of students;

- the learning process is based on real life situations;

- leaning is based on teamwork (in some countries based on projects);

- raising the intercultural awareness of both students and teachers;

- increasing employability;

- breaking various kinds of prejudice and fear of travelling outside the home country;

- $\quad$ acquiring communicative skills and patterns (Metodický portál, 2013).

Possible negative aspects:

- a high level of time consumption for material preparation;

- students/teachers do not have the relevant level of foreign language knowledge;

- not enough information on the CLIL method;

- lack of motivation to use the CLIL approach;

- reluctance of using the method;

- training courses are not available on a regular basis (Comenius and Grundtvig programs organize CLIL courses during the summer holidays).

\section{Requirements on Teachers}

There are books describing the basic requirements for skills and competences of teachers using the CLIL approach (Bertaux et al., 2010; Marsh et al., 2010). These cover e.g. foreign language acquisition by non-language teachers, becoming acquainted with a certain non-language subject (language teachers), the role of teamwork during lessons, CLIL methodology, the way of assessment, how to provide feedback, dealing with multicultural groups, didactics in a multinational group, etc. 
The best option for teachers is to have a degree in a particular subject (e.g. economics) and at the same time a degree in a second language; or a willingness to develop or deepen their knowledge from the other subject. There is also the option of the so-called team teaching, i.e. a language teacher cooperates with a subject teacher. However, this possibility is rather demanding for lesson preparation, communication between the teachers and, moreover, it considerably increases the financial cost of a lesson.

The figure below shows several areas (vast) regarding the CLIL education of teachers. A lot of fields are to be taken into account when implementing the CLIL approach, such as careful lesson planning, awareness whether the plans correspond with the subject curriculum or the learners' needs, to know how to create the context for efficient learning using lead-in and follow-up activities. Furthermore, a teacher ought to clarify the way of assessment and so on.

Fig. 2 Requirements on Teachers

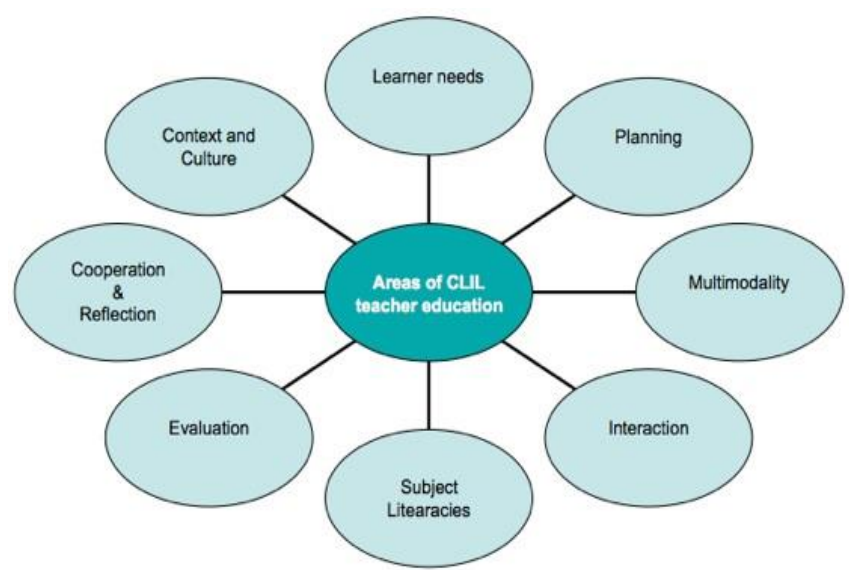

http://www.google.cz/imgres?imgurl=http://sciencemaths-clil.eu/wpcontent/uploads/2010/05/sm_clil_star_mocdified1.jpg\&imgrefurl=http://science maths-

clil.eu/?page_id\%3D2\&h=663\&w=1094\&sz=136\&tbnid=8usnua4lbRgXbM:\&t bnh $=67 \&$ tbnw $=111 \&$ zoom $=1 \&$ usg $=+91$ NRUnXJwLJqUSLdCWeXgyUgVq4= $\&$ docid=iW1QxcwMnsKKZM\&sa=X\&ei=QLeDUbz9Jc_KtAaj_ICwCA\&ved= 0CFkQ9QEwBw\&dur=1693, 29/4/2013 


\section{An Example of a Lesson of Recruitment in Economic Subjects}

The topic of recruitment has been chosen for its variety of use in several fields (economic, technical, etc.). The topic can be used in both hard and soft CLIL versions, including some alternations depending on the main lesson objective.

This lesson has been designed for students of economic subjects. The class consists of approximately 20 students; seven of them are foreigners from Croatia, France, Turkey, Greece, and Kazakhstan. The level of English, concerning all students, is between B1 and B2 according to the Common European Framework of Reference for Languages. The students are used to working in international groups enjoying the national diversity as well as age similarity.

The main emphasis of the example lesson is on pair work or group work to enable students to acquire teamwork skills.

\section{Recruitment}

The first task for students is to brainstorm what areas the expression recruitment can cover.

The students are given the visual prompt below and they are asked to discuss the questions in pairs.

$$
\text { Secretary wanted }
$$

1. Think of the qualities a good secretary should have. Why?

2. Read the article and discuss in pairs what title would be suitable for each paragraph.

Good employees are hard to find. You place an advertisement and then wait for the applications to come flooding in. In a day or two, you're pleased to see the stack of applications waiting for you? How many are there: 100, 200? or more? Well done! What a response!

When you begin to look through the applications, you may feel disappointed. You think: Why did this guy apply? He doesn't have the experience you asked for. What? She's never even done this kind of job? Is this candidate joking? $\mathrm{He}$ probably chose the wrong advertisement. 
To find and hire the best candidate is not an easy job. Most of the applicants won't have the required qualifications and then it is the matter of selecting the best of these. So what qualities are important when interviewing? The following qualities are most likely to appear on a list for consideration: hardworking, someone with positive attitude, experienced, initiative, team player, someone responsible and someone who is stable (Pettinger, 2011).

3. Answer the following questions.

a) Why is it difficult to find good employees?

b) What are the most common problems with applications?

c) What is the reason for making compromises when selecting new employees?

d) Do you agree with the listed qualities in the last paragraph? Would you add any?

4. Imagine: a) you are an interviewer and your schoolmate is an interviewee. Talk about:

- Experience

- Duties

- Expectations

- Possible questions

b) In pairs draft a structure of a European $\mathrm{CV}$.

5. In small groups, find out the recruitment procedure in neighbouring countries and present the differences and similarities.

\section{Conclusion}

The use of Content and Language Integrated Learning is considered a new pattern in language and subject teaching as for integrating both parts (linguistic and factual) into teaching. Next, it responds to the needs of globalization and uses lingua franca as a means of communication within multinational communities.

The practical employment of this teaching approach is expected, although it is quite demanding for the participating learners and teachers. CLIL emphasizes effective learning outcomes, cognitive knowledge, critical thinking, and real life 
use of a language in the subject's background. Learners acquire the basic structures for communication in a foreign language which is being developed.

\section{References}

BERTAUX, P. et al. The CLIL teacher's competences grid [online]. Available from: http://lendtrento.eu/convegno/files/mehisto.pdf

COLY, D., HOOD, P. and MARSH, D. CLIL: Content and language integrated learning. Cambridge: Cambridge University Press, 2010.

CRYSTAL, D. How Language Works. London: Penguin Books, 2007.

KALHOUS, Z. and OBST, O. et al. Školni didaktika. Praha: Portál, 2002.

PETTINGER, R. Management for Dummies. 2nd revised edition. John Wiley \& Sons, 2011.

PRŮCHA, J. Interkulturni komunikace. Praha: Grada. 2010.

http://clanky.rvp.cz/clanek/c/Z/16553/clil-aneb-prirozene-pouziti-cizihojazyka-pro-realnou-komunikaci.html/http://google.com/images [viewed 27 April 2013].

http://en.wikipedia.org/wiki/Content_and_language_integrated_learning [viewed 27 April 2013]. 